\title{
Educación superior y migración boliviana. Trayectorias educativas de jóvenes provenientes de familias migrantes bolivianas
}

\author{
Higher education and Bolivian migration. Educational trajectories of young \\ people from Bolivian migrant families
}

\section{Melina Morzilli \\ melinamorzilli@gmail.com \\ Universidad Nacional de La Plata - CONICET, Argentina}

Recepción: 10 Mayo 2021

Aprobación: 02 Septiembre 2021

Publicación: 01 Noviembre 2021

Cita sugerida: Morzilli, M. (2021). Educación superior y migración boliviana. Trayectorias educativas de jóvenes provenientes de familias migrantes bolivianas. Anuario del Instituto de Historia Argentina, 21(2), e146.

https://doi.org/10.24215/2314257Xe146

\begin{abstract}
Resumen: Este trabajo tiene como objetivo realizar una revisión sistemática sobre los estudios que han buscado analizar la inclusión socioeducativa de la población migrante boliviana en el ciclo superior. Al mismo tiempo, analiza las distintas perspectivas desde donde fue abordado el tema y pretende integrar los resultados de los estudios referidos al mismo. Por último, se realizan reflexiones finales intentando identificar tendencias, contradicciones, relaciones y visualizar las dimensiones que no han sido estudiadas.
\end{abstract}

Palabras clave: Trayectorias Educativas, Ciclo Superior, Jóvenes Migrantes Bolivianos/as, Horticultura Periurbana Platense.

Abstract: The objective of this work is to carry out a systematic review on the studies that have sought to analyze the socioeducational inclusion of the Bolivian migrant population in the upper cycle. At the same time, it analyzes the different perspectives from which the subject was approached, and seeks to integrate the results of the studies on the subject. Finally, final reflections are made trying to identify trends, contradictions, relationships and visualize the dimensions that have not been studied.

Keywords: Educational Trajectories, Higher Cycle, Young Bolivian Migrants, Horticulture Periurban Platense.

\section{INTRODUCCIÓN}

Este trabajo tiene como objetivo realizar una revisión sistemática sobre los estudios que han buscado analizar la inclusión socioeducativa de la población migrante boliviana, ${ }^{1}$ desde el abordaje de las trayectorias educativas en el ciclo superior de jóvenes de familias provenientes de Bolivia. Al mismo tiempo, analiza las distintas perspectivas desde las que fue abordado el tema, y pretende integrar los resultados de los estudios referidos al mismo. Por último, se realizan reflexiones finales con intención de identificar tendencias, contradicciones, relaciones, y visualizar las dimensiones que no han sido estudiadas.

A partir de la investigación realizada en mi tesis doctoral pude comprobar, para los casos analizados en la misma, ${ }^{2}$ y como ya habían señalado algunas investigaciones (Attademo, 2009; Pineda, 2011; Cieza, 
2012; Lemmi, 2015), que los/as jóvenes migrantes bolivianos/as insertos en la producción de hortalizas del periurbano platense (provincia de Buenos Aires, Argentina) son asiduos demandantes de la educación media pública, como parte de las estrategias familiares de vida para superar las condiciones de vulnerabilidad social en las que se encuentran. Desde fines del siglo XIX, y con sus particularidades en distintos momentos históricos, la promesa de igualdad de la educación (Padawer, 2008) se correspondió con prácticas de acceso y permanencia en las escuelas, tanto en el nivel inicial como en el medio, y fueron entendidas por las familias de migrantes bolivianas como una herramienta para el ascenso social (Ringuelet et al., 1991; Benencia, 2005, 2012; Benencia y Quaranta, 2018; Lemmi, Morzilli y Moretto, 2018; Morzilli, 2019). En las conclusiones de mi tesis observé que, como parte de sus estrategias de movilidad social ascendente, los/as jóvenes y sus familias migrantes bolivianas, que se asientan en el periurbano platense, a pesar de que trabajan duramente y viven en condiciones de vulnerabilidad social y económica realizan grandes esfuerzos para que los/as integrantes más jóvenes de sus núcleos familiares puedan acceder a la escuela media pública, egresen de la misma, y así puedan acceder a estudios en el ciclo superior. Entienden esto como parte necesaria para transitar su "escalera" de ascenso social, y, a su vez, lograr una bifurcación en la escalera boliviana ${ }^{3}$ (Morzilli, 2019).

Es así que encontramos jóvenes (algunos/as migrantes y otros/as nacidos/as en Argentina, pero que integran familias con historia de migración) que transitan la escuela media pública de una manera que el sistema registra como exitosa, al mismo tiempo en que trabajan con sus padres en las quintas y tienen aspiraciones por acceder, permanecer y egresar en estudios del ciclo superior (Terigi, 2009).

Sobre esta última cuestión pretendo focalizarme en este trabajo, profundizando en un aspecto clave para el país en términos de estrategias y metodologías para la promoción de la inclusión social y educativa, como es, en este caso, el de los derechos educativos al ciclo superior de los/as migrantes bolivianos/as en Argentina. Para ello, este trabajo de enfoque interpretativo se articula en torno a las investigaciones existentes sobre los estudios que abordaron migrantes bolivianos/as y acceso al ciclo superior por parte de los/as mismos/as.

\section{Metodología y FUentes}

El diseño de la investigación aquí presentada es de carácter cualitativo y el enfoque es interpretativo, por ser el más adecuado para los objetivos que se persiguen en este trabajo. Las estrategias de recolección fueron búsquedas tanto en Google Scholar, como también en repositorios digitales de las universidades de Argentina, donde se almacena gran parte de las tesis de posgrado con la referencia de las palabras clave: educación universitaria y migración boliviana.

Como se ha señalado en el apartado anterior, mis estudios doctorales me aproximaron y acercaron a la temática planteada aquí. Las conclusiones de mi investigación me llevaron a preguntarme por el acceso, permanencia y egreso de los/as migrantes bolivianos/as en los estudios superiores.

Los estudios seleccionados revisados, junto con las estrategias de búsqueda, fueron todos aquellos estudios que abordaron en alguno de sus objetivos generales y/o específicos las relaciones entre la educación superior y poblaciones de migrantes bolivianos/as, o bien, aquellos en los que se describían testimonios de migrantes bolivianos/as cursando o pretendiendo cursar estudios superiores. Se excluyeron investigaciones que no se referían al ámbito geográfico nacional argentino, debido a que el objetivo final de este trabajo es encontrar las vacancias de este tipo de estudios para el ámbito nacional.

En este sentido se encontraron catorce investigaciones.

\section{ANTECEDENTES (MARCo TEÓRICO Y ANTECEDENTES)}

En los últimos años las ciencias humanas y sociales se han convertido en un campo de convergencia de investigaciones que han abordado estudios sobre migración y educación. En la presente propuesta, a partir 
de esos antecedentes, se pretende aportar con una revisión de los estudios sobre inclusión socioeducativa en el ciclo superior de la población migrante boliviana intentando identificar tendencias, contradicciones, relaciones y visualizar las dimensiones que no han sido estudiadas.

\section{Estudios específicos sobre migración boliviana y acceso al ciclo superior de educación}

En esta línea de investigación ubicamos a Sosa (2016), quien tuvo como objetivos caracterizar el rol del Estado argentino en relación con las políticas educativas que impactan en la población de migrantes, en particular en el nivel superior, así como avanzar en la cuantificación del número de estudiantes extranjeros en la educación superior de Argentina y su distribución territorial, en el contexto de los procesos migratorios recientes.

Desde la Sociología de la educación y con metodología cuantitativa, a partir de la información recogida en los sucesivos relevamientos anuales que realiza el Ministerio de Educación de la nación en colaboración con los de todas las provincias y con la ciudad de Buenos Aires - 14 de carácter censal-, sostuvo que los extranjeros representan el $1 \%$ en el nivel superior no universitario.

En cuanto a la participación de los alumnos extranjeros en la matrícula de la educación superior, observó que el sistema en Argentina está conformado por dos subsistemas. Por un lado, la educación superior no universitaria, integrada por las instituciones que brindan formación docente y/o formación técnico profesional. Y, por el otro, existe un sistema universitario conformado por 106 instituciones públicas y/o privadas. Dio cuenta, además, de que, en el subsistema de la educación superior, los alumnos se distribuyen mayoritariamente en instituciones estatales y dedicadas a la formación docente. No obstante, es muy importante la participación privada y del alumnado que realiza estudios de formación técnico-profesional. En la formación docente más de siete de cada diez estudiantes cursa en instituciones estatales, mientras que en la formación técnico profesional ocurre lo contrario: casi dos terceras partes del alumnado concurre a instituciones privadas.

La información muestra que, como en el resto de los niveles de enseñanza, también en este subsistema de la educación superior (el no universitario) hay participación de alumnado extranjero, y que, en términos porcentuales, en el "total país" tal participación es muy reducida.

Puede apreciarse que entre los alumnos extranjeros que cursan el nivel superior no universitario también es mayoritario el peso porcentual de los que nacieron en países limítrofes o Perú, pero que la participación porcentual de alumnos de otras nacionalidades $(25,7 \%)$ es muy superior a la que se advierte entre los otros niveles de enseñanza.

Si bien la participación de los alumnos extranjeros en la matrícula del nivel superior no universitario continúa siendo muy reducida, advirtió que entre el 2003 y el 2009 se duplicó. Mientras que la matrícula total inscrita en el nivel superior no universitario creció en el periodo un 18,2 \%, la matrícula extranjera se incrementó un $135 \%$.

Respecto a la distribución del total de alumnos y de los extranjeros que cursan estudios de nivel superior no universitario entre 2003-2009 sostuvo que en 2003 los migrantes bolivianos representaban el 26,6\% del total de extranjeros que estudiaban en este nivel (0,5\%); en 2009, el 1,1\% era el total de extranjeros que estudiaba en ese nivel, mientras que, de estos, el 22,2 \% eran migrantes bolivianos/as.

A su vez, sostuvo que la distribución territorial de los extranjeros se concentra fundamentalmente en dos jurisdicciones, y, consecuentemente, lo mismo ocurre con la matrícula escolar extranjera, lo que contribuye a hacer más visibles más a estos alumnos. En el caso del nivel superior no universitario la concentración territorial de los alumnos extranjeros se profundiza. Si bien la mayoría de los migrantes nacidos en países limítrofes reside en la provincia de Buenos Aires, casi seis de cada diez alumnos extranjeros que estudia en establecimientos de nivel superior no universitario lo hace en instituciones situadas en la ciudad de Buenos Aires. 
Ahora bien, dentro de la educación superior, el subsistema universitario es el que concentra a la gran mayoría de alumnos del nivel. A través de 106 instituciones (87 universidades y 19 institutos universitarios) atiende a 1.650 .180 alumnos. Ocho de cada diez estudiantes universitarios asisten a instituciones estatales (CIIE, 2009).

Respecto a los estudiantes extranjeros que cursan carreras de grado o posgrado en universidades argentinas, oficiales o privadas, la última información disponible actualmente con cobertura nacional corresponde a 2006. En ese momento el sistema universitario argentino contaba con 26.354 estudiantes extranjeros. El relevamiento universitario consideraba "estudiantes extranjeros" a aquellos que no eran ciudadanos argentinos (extranjeros con o sin residencia, extranjeros con visa de estudios o turismo).

En ese año, la tasa de estudiantes extranjeros de grado y pregrado era del $1,12 \%$, con una tasa más alta en las universidades privadas (2,55\%). En los posgrados la tasa alcanzaba al 6,76\%, con 5,08 \% en las instituciones de gestión estatal y un 12,35\% en las universidades privadas (CIIE, 2006).

Debido a que no disponía de información más actualizada para la totalidad del país, analizó el número de estudiantes extranjeros en la Universidad de Buenos Aires con base en los datos recogidos por el Censo Nacional de Alumnos de dicha institución, realizado en 2011.

La Universidad de Buenos Aires (UBA) es la casa de altos estudios más grande del país; alberga a alrededor de 300 mil estudiantes de grado y posgrado. Según la información recogida en el último Censo de Alumnos de esta institución, realizado en 2011, en ese año se registraban 10.646 alumnos de grado que declaraban ser extranjeros y que representaban el $4 \%$ del total de alumnos de grado de esa entidad académica. Entre los estudiantes extranjeros predominaban aquellos de los países limítrofes, como Bolivia, y no limítrofes, como Perú (8.123 estudiantes), y las unidades académicas que presentaban mayor presencia de estudiantes extranjeros eran el Ciclo Básico Común (7,2 \%), la Facultad de Odontología (6,0 \%) y la de Medicina (5,7 \%). En dichas unidades académicas los estudiantes de los países limítrofes (como Bolivia) y no limítrofes (como Perú) predominaban entre los extranjeros.

De los 10.646 estudiantes de grado que declaraban tener nacionalidad extranjera, el 25,3\% correspondía a Perú, luego los provenientes de países limítrofes: Bolivia (18 \%), Paraguay (11,3\%), Brasil (8,8 \%) y Chile (8,2 \%). Siguen en importancia los de Colombia, Uruguay y Estados Unidos con el 6 \%, 4,8 \% y 2,4 \% respectivamente.

Concluye Sosa, tal como sucede en los otros niveles de enseñanza, la matrícula extranjera en educación superior no universitaria se concentra (al igual que la totalidad de la población migrante) en la ciudad de Buenos Aires y en la provincia de Buenos Aires, aunque, a diferencia de lo que ocurre en otros niveles de enseñanza, el número absoluto de alumnos extranjeros que asisten al nivel superior no universitario en la ciudad de Buenos Aires es mayor que el que cursa en la provincia.

Rosas (2014) reflexionó, a través de una metodología cualitativa con entrevistas, sobre distintos aspectos de la experiencia migratoria de un grupo de población que ha concitado escasa atención: los/as jóvenes. En sus páginas ha señalado algunos aspectos fundamentales para la comprensión del fenómeno, así como para el armado de una agenda analítica y política que atienda las especiales condiciones de los adolescentes y jóvenes migrantes.

Si bien las trayectorias migratorias pueden ser diversas (porque dependen de sus características y de los condicionamientos de los contextos sociales, económicos, políticos y culturales de los orígenes, tránsitos y destinos), se detiene en algunas de las experiencias más salientes de los/as jóvenes ubicados en los tres principales destinos de los latinoamericanos: Estados Unidos, España y Argentina.

Muchos jóvenes peruanos mantenían expectativas de realizar estudios superiores en Argentina. Sostuvo que, lamentablemente, son pocos los casos de jóvenes latinoamericanos migrantes incorporados en establecimientos educativos de nivel superior, ya sean terciarios o universitarios. En Argentina, en los últimos años han arribado más jóvenes de países sudamericanos y centroamericanos con la intención de realizar estudios universitarios de grado y especialmente de posgrado. Estos/as jóvenes no pertenecen a los grupos 
migratorios mayoritarios, sino que provienen de sectores medios altos, que, en muchos casos, cuentan con apoyo parental para realizar los estudios.

En cambio, los/as jóvenes de los grupos migrantes mayoritarios - provenientes de Paraguay, Bolivia y Perútienen menos chance de incorporarse y desarrollar una carrera terciaria o universitaria. Con independencia de sus expectativas escolares, las familias de estos jóvenes generalmente no tienen posibilidades de sostener las carreras de sus hijos/as, y a ellos/as se les hace muy complicado enfrentar las duras condiciones laborales y de vida que les impone Argentina al mismo tiempo que realizan una carrea superior.

Por otra parte, Magliano (2013) analizó la migración contemporánea de mujeres bolivianas hacia Córdoba, Argentina. En particular, buscó reconstruir los diversos fragmentos que componen las trayectorias de vida de estas mujeres y los roles que asumen en el proyecto migratorio, a partir de las imágenes, prácticas y representaciones que recuperan y reafirman su propia condición de mujeres, de bolivianas y de migrantes. Mostró que, a partir de recuperar la experiencia migratoria de las mujeres bolivianas migrantes, es posible identificar las estrategias que las familias bolivianas despliegan en el marco del desarrollo y consolidación del proyecto migratorio hacia Córdoba. Para ello, optó por una metodología cualitativa que combinó observación participante y entrevistas en profundidad con migrantes bolivianos, mujeres y varones, que llegaron a Córdoba desde mediados del siglo XX hasta la actualidad. La información que recabó para este trabajo de campo, realizado en la ciudad de Córdoba durante los períodos 2005-2007 y 2009-2010, la extrajo de 30 entrevistas en total, en las que buscó que las/os entrevistadas/os reconstruyeran su historia personal a partir de lo que consideraban más significativo.

Sostuvo que se establecieron diferencias entre aquellas migraciones que se movilizaron hacia mediados del siglo XX y las que lo hicieron desde los años ochenta y noventa en adelante. De acuerdo con los relatos de las/ os migrantes, a mediados del siglo XX, además de la siempre presente cuestión laboral, un amplio porcentaje de los migrantes bolivianos que llegaban a la ciudad de Córdoba poseía un perfil orientado a las necesidades de formación profesional, especialmente los varones, mientras que aquellos que arribaron en las últimas décadas del siglo XX se circunscribieron a una migración principalmente de carácter laboral, que se ha movilizado en busca de mejores condiciones de vida. Esta diferenciación distingue, en términos simbólicos, la migración de mediados de siglo y la denominada migración nueva o reciente, que adquiere mayor dinamismo desde la década de los noventa en adelante.

Los testimonios pusieron de relieve que la elección de Córdoba como destino se debe a diversos factores sociales, históricos y económicos. Entre ellos, se destacó la ubicación geográfica de la ciudad (y también de la provincia), que en la década de los sesenta se convirtió en un nudo neurálgico del intercambio comercial del país, y que además posibilitó que para muchos migrantes bolivianos la ciudad de Córdoba fuera un lugar de paso para luego dirigirse a Buenos Aires o continuar el recorrido hacia el sur del país (Domenach, Celton y Bologna 1998). A su vez, la tradición educativa cordobesa, en especial su universidad, ha funcionado también como un motor de atracción a la hora de elegir esta ciudad. Además de estos factores, las redes sociales entre origen y destino han jugado un rol significativo en el arribo a Córdoba, pues, como se desprende de los relatos, muchos/as migrantes tenían familiares, amigos y vecinos viviendo en la ciudad previamente a su llegada.

Entre las acciones que las mujeres migrantes promueven en la ciudad de destino está el acceso a la educación de los hijos, lo cual se torna fundamental para la estabilidad y consolidación del proyecto migratorio. El rol de las mujeres bolivianas adultas, como impulsoras principales de los estudios de sus hijos, las coloca en un lugar relevante frente a las necesidades de integración:

Yo siempre digo que nosotros nos vinimos con una valija llena de ilusiones, de proyectos para poder salir adelante, con muchas expectativas de seguir estudiando. Según lo que nos decían, lo que nos llamaba mucho la atención era la Universidad de Córdoba. Entonces, con todo eso vinimos nosotros, primero mi marido, después yo con mis hijos chiquitos, pero llegamos acá y era otra la realidad. Con lo que primero chocamos fue con el documento, que no lo teníamos y no podíamos trabajar, no podíamos inscribir a los chicos al colegio porque no teníamos la documentación necesaria, o sea que fue terrible lo que hemos sufrido. Pero ahora ya tengo a mi hija, que ese era el sueño que yo quería cumplir, que mis hijos lleguen a la universidad 
en Córdoba. Mi hija ya es profesional, y mi hijo se está preparando para entrar a la universidad (Elena, boliviana, 52 años [llega en 1990], Córdoba, mayo de 2006).

Entonces, subraya que, en el ámbito de la comunidad boliviana en Córdoba, la educación funciona como un factor de diferenciación, a la vez que como expresión de éxito del proyecto migratorio, en tanto se la vincula directamente a la posibilidad de movilidad social ascendente. Así lo explicaba Irma, cuando sostenía: "Para nosotros lo más importante es que nuestros hijos estudien; siempre buscamos que estudien (...) que vayan a la escuela, si es posible a la universidad, y a veces la familia se sacrifica para que puedan estudiar" (Irma, boliviana, 37 años [llega en 1996], Córdoba, diciembre de 2009).

En los testimonios de las migrantes bolivianas se plantea indistintamente el hecho de ser varón o mujer a la hora de pensar en la inversión en educación. Si se tiene en cuenta el lugar central que ocupan los hijos en el proyecto migratorio, el valor otorgado a la educación se articula a ciertas decisiones que se van tomando en pos de facilitar su acceso a los niños. El apoyo de los padres para que los hijos permanezcan el mayor tiempo posible dentro del sistema educativo formal no necesariamente se vincula con su nivel de formación. En el trabajo de campo realizado en Córdoba se constató que la pertenencia de clase de las familias no supone una valoración diferenciada respecto de la educación como factor de ascenso social. Al contrario, en todos los estratos sociales la educación aparece como un factor clave. No obstante ello, la pertenencia de clase de los padres puede determinar, en muchos casos, el tiempo de permanencia de los hijos en el sistema escolar formal.

Martínez Espíndola (2010) realizó una investigación en la que pretendió conocer las representaciones existentes acerca de las experiencias migratorias, tal como se manifiestan en los discursos de mujeres bolivianas residentes en Mendoza. Para acceder a una comprensión lo más completa posible de las migraciones de mujeres bolivianas a la provincia de Mendoza, consideró pertinente detenerse en algunos aportes acerca del proceso de feminización de las migraciones. Por otro lado, le resulto fundamental incorporar resultados de algunos análisis históricos acerca de la migración de personas de Bolivia en Argentina y en Mendoza. El problema de investigación cuestiona qué significaciones construyen las integrantes de la comunidad boliviana residentes en Mendoza en torno a su experiencia migratoria, teniendo en cuenta su condición de mujeres procedentes de Bolivia, pertenecientes a sectores populares, y los procesos de configuración y reconfiguración de identidades culturales en el contexto posmigratorio. Asimismo, ha intentado dar respuesta a múltiples interrogantes relacionados al problema central, como son las motivaciones personales de la migración, la trayectoria espaciotemporal recorrida y las experiencias laborales vividas.

El objetivo general de su investigación consistió en analizar los significados que construyen las mujeres en torno a su condición de género femenino migrante de origen boliviano, con el fin de descubrir qué lazos permiten anudar la clase social, la nacionalidad, la etnia y el género como categorías analíticas, que, de manera interrelacionada, configuran la experiencia migratoria de las mujeres entrevistadas imprimiéndole características particulares.

Indagó en las subjetividades de mujeres bolivianas que dejaron su país de origen y vivían al momento del trabajo de campo en la provincia de Mendoza, con interés por conocer, desde su perspectiva, cuáles habían sido sus experiencias como migrantes portadoras de identidades de género, de clase social e identidades culturales específicas. En consecuencia, resultó imprescindible la elección de una metodología cualitativa que permitiera reconstruir el universo de significaciones de las actoras involucradas en los procesos bajo estudio.

De acuerdo con los fines de la investigación, la muestra poblacional se conformó por mujeres de distintas edades nacidas en Bolivia, que migraron a Argentina y residían en Mendoza. El trabajo de campo se realizó en los puestos ambulantes de las entrevistadas, que tienen lugar en el centro de la ciudad de Mendoza y en un barrio periférico del departamento de Las Heras. El límite temporal de la investigación se ubicó en el año 2009.

El nivel de instrucción alcanzado al momento del operativo censal revela varias diferencias entre varones y mujeres, y coloca a estas últimas en situaciones educativas menos favorables. Tanto varones como mujeres presentan la misma distribución según niveles educativos, con una participación que disminuye 
considerablemente desde el nivel de instrucción primario al universitario. Sin embargo, la cantidad de mujeres sin instrucción o con primario incompleto supera ampliamente a la de varones; es del $67 \%$ y del $54 \%$, respectivamente. A medida que asciende el nivel de instrucción desciende la participación de las mujeres en mayor medida que la de los varones. El nivel de instrucción del ciclo superior para ambos géneros es del $1 \%$.

Consideró importante mencionar que, en gran parte de los casos, las mujeres tienen más de 50 años y el factor generacional no debe dejarse de lado en el análisis, ya que, según los relatos, apreciamos que la escolarización de los niños y niñas ha cobrado importancia con el tiempo. Es decir, interviene la variable histórica, que permite vislumbrar la modificación de pautas culturales en lo que respecta al valor de la escolarización en determinados contextos socioculturales.

Según los discursos analizados, es notable la diferencia entre la escolarización de las mujeres entrevistadas y la de sus hijos. Cuando relatan sus infancias, en varias ocasiones se hace referencia a que los padres decidían si ellas irían a la escuela o se dedicarían a trabajar.

También aparece, en alguno de los casos, la importancia de la cuestión de género en esta decisión de los padres, quienes priorizaron la escolarización de los hijos varones y el trabajo en el caso de las niñas.

De manera por completo diferente, las entrevistadas muestran un gran interés por que sus hijos e hijas asistan a la escuela y completen su escolarización hasta niveles superiores. Notamos en los discursos de las mujeres un sentimiento de "cuenta pendiente" con la escolarización. Esto se manifiesta en el deseo de haber terminado la primaria, la secundaria o la universidad, y el proyecto de comenzar la primaria en algunos casos, proyecto que se ve dificultado por las obligaciones laborales y domésticas.

Sala (2008) sostuvo que, en el último cuarto del siglo XX, Argentina aún concentraba el mayor número de migrantes intrarregionales del Cono Sur de América Latina, y en Brasil se incrementó la presencia de migrantes bolivianos, paraguayos, uruguayos y argentinos. A partir de los censos de los respectivos países, en su trabajo cuantitativo identificó diferencias y transformaciones en el perfil educativo y laboral de los nuevos y viejos migrantes regionales censados en Argentina y Brasil. Analizó la distribución según escolaridad y ocupación de cohortes migratorias, determinadas por el año en el que fue fijada la residencia en ambos países; mostró diferencias entre los trabajadores migrantes y nativos. Concluyó que en Argentina la mayor escolaridad de los nuevos migrantes regionales no alteró en esencia la segregación en ocupaciones de menor calificación, en ramas como la agricultura, construcción, manufactura y el servicio doméstico.

A comienzos del siglo XXI Argentina aún es un país con una tradición marcada en la captación de migrantes poco calificados de la región. Entre quienes se radicaron en Argentina a partir de los años setenta cayó la participación de migrantes con instrucción muy baja, y creció la de quienes tenían escolaridad baja y media. La escolaridad de las/os migrantes bolivianas/os que se radicaron durante el período 1990-2000/1 tendió a aproximarse a la de la población nativa.

Por último, Sangiácomo (2002) realizó una investigación que tuvo por objeto el estudio de la inmigración boliviana en la ciudad de La Plata y su evolución en treinta años (1908-2000). Además del abordaje de la problemática migratoria en la región en referencia a su incorporación y trayectorias en el mercado de trabajo, le interesó indagar sobre otras formas de inserción que, aunque no involucraran volúmenes tan significativos como los de la migración laboral, constituían movimientos de población que hacían también de Argentina un polo receptor y de Bolivia uno expulsor dentro del sistema migratorio que conformaban junto a Chile, Uruguay y Paraguay, y que podían dar cuenta de la vinculación histórica que se ha establecido entre ambos países. Por ello toma el caso de los/as estudiantes de origen boliviano que eligen completar sus estudios en la Universidad Nacional de La Plata y hace un análisis de indicadores cuantitativos referidos a los/as estudiantes bolivianos/as que vienen a esta ciudad con el objetivo de realizar sus estudios universitarios. Analizó la evolución de las variables de ingreso y egreso tanto de los/as estudiantes bolivianos/as como del total de los/as alumnos/as de la Universidad con el objetivo de determinar si existían particularidades en el comportamiento del colectivo migrante, en relación a la población universitaria general, y también en relación a determinados indicadores como edad, género, preferencia por carreras y lugar de procedencia, para definir cierto perfil del 
estudiante boliviano/a. Se detuvo también en la comparación de la evolución histórica del ingreso y el total de radicaciones bolivianas en nuestro país, porque consideraba que podía dar cuenta de una relación entre esta migración particular y la migración de carácter laboral.

La presencia de estudiantes bolivianos/as en la Universidad Nacional de La Plata a lo largo del período estudiado confirma la existencia de un constante movimiento de población desde Bolivia a esta ciudad. Esta migración atravesó por diferentes etapas en cuanto a su volumen, aunque mantuvo en el tiempo ciertas características, como su lugar de procedencia, una mayor presencia masculina, un promedio estable en la edad de ingreso y una alta concentración en determinadas carreras.

Si la evolución tanto de ingresos como de egresos del total de alumnos/as de esta universidad presenta una tendencia positiva, en el caso de los/as bolivianos/as la tendencia es opuesta, aunque mucho más marcada en los ingresos que en los egresos, donde se aprecia cierta estabilidad en comparación con los diferentes ciclos por los que ha atravesado el ingreso.

Debido a que el volumen de egresos no ha variado sustancialmente en el tiempo -lo que sí ha sucedido con los ingresos-, planteó que el acceso a la universidad tal vez no siempre se vincule con la intención de realizar una carrera, sino que podría ser el vehículo legal para poder permanecer en el país con fines laborales, viendo que su evolución se emparenta con la de las radicaciones generales.

\section{Estudios sobre migración boliviana con indicios de algunos testimonios al acceso al ciclo superior de educación}

En esta otra línea de investigaciones, en primer lugar, se encuentra Morzilli (2020; 2019), quien realizó dos investigaciones. En la primera buscó dar cuenta de la incidencia en las trayectorias socioproductivas en las trayectorias escolares de jóvenes de familias migrantes bolivianas que se encuentran en situaciones de vulnerabilidad social y económica. Realizó un estudio de caso situado en el periurbano hortícola platense durante la cohorte 2011-2017, en una escuela media pública, en la que un porcentaje relevante (casi la mitad de la matrícula) de alumnos/as eran migrantes bolivianos/as o hijos/as de migrantes bolivianos/as.

En la segunda investigación específicamente se propuso dar cuenta de la incidencia del capital cultural institucionalizado ${ }^{4}$ de las familias, las relaciones intrafamiliares y los mandatos paterno-maternales en las trayectorias escolares de jóvenes de hogares migrantes bolivianos dedicados a la horticultura, que se encuentran en situaciones de vulnerabilidad económica y social.

En ambas investigaciones, en relación al marco teórico utilizado, se centró en la propuesta teórica de Bourdieu denominada constructivismo-estructuralista, con la cual buscó superar la falsa dicotomía objetivismo/subjetivismo (Bourdieu, 1988).

Estos estudios se basaron principalmente en el uso de fuentes orales inéditas. Para su abordaje se requirió una estrategia metodológica cualitativa (descriptiva y analítica) con enfoque histórico-etnográfico. Si bien la estrategia metodológica que privilegió fue de carácter cualitativa, la misma la combinó con una metodología cuantitativa, con el objetivo de profundizar el conocimiento y no de validar los datos.

En cuanto a la metodología cualitativa, utilizó la técnica de historia de vida con enfoque históricoetnográfico apelando a las fuentes orales, y realizó entrevistas en profundidad (semiestructuradas) y observación participante a 21 jóvenes y 5 familias, a partir de una muestra teórica intencional, por bola de nieve; a su vez, realizó encuestas a dichos/as jóvenes.

Mientras tanto, para la metodología cuantitativa utilizó como fuente primaria los datos estadísticos de una escuela secundaria pública elegida en el periurbano platense. Debido a que las instituciones educativas son productoras de información de base que luego se utiliza para componer la estadística educativa, gestionó y logró la autorización para revisar los archivos con documentación de la institución para acceder a información 
sobre inscripciones, asistencias y calificaciones de los/as alumnos/as, como también datos ocupacionales, demográficos y educativos de sus padres y madres.

En la primera investigación observó una dinámica entre las trayectorias escolares y socioproductivas diferente a los resultados de otras investigaciones, en tanto que, por un lado, varios autores sostuvieron que el trabajo conlleva al abandono escolar (Bertranou, 2002; López, 2002; Binstock y Cerrutti, 2005; Bracchi, Gabbai y Causa); por otro lado, según algunos estudios (Macri, 2005; Filmus, 2010), si bien una parte de los/as jóvenes que trabajan asiste a la escuela, el ausentismo y la sobreedad inciden negativamente en esas trayectorias escolares y en sus logros educativos.

Observó en los casos que analizó que todos/as trabajan y asisten a la escuela, y en los únicos dos casos de existencia de sobreedad, la misma se dio en un caso en la infancia por razones de lejanía del hogar a la escuela, y en el otro por cuestiones de salud; es decir, la sobreedad no fue producto de las trayectorias socioproductivas.

Pudo ver que los casos abordados habilitan nuevos interrogantes para reflexionar sobre diferentes resultados, y deja abierto el debate para indagar sobre otras posibles variables que pueden incidir en las trayectorias escolares independientemente de las trayectorias socioproductivas. Es decir, concluyó que las trayectorias socioproductivas no incidieron negativamente en sus trayectorias escolares y que los/as jóvenes poseían trayectorias escolares exitosas en el nivel medio.

Mientras tanto, en la segunda investigación dio cuenta de un quiebre de herencia intergeneracional a nivel cultural institucionalizado, ya que las madres y padres de los/as jóvenes cuyos casos fueron analizados quedaron en el nivel primario, mientras que sus hijos/as accedieron al nivel medio. Fue así que comenzó a registrar, a partir de las entrevistas con las familias, que las mismas le dan a la escolaridad del nivel medio un valor muy importante.

En el caso de las madres de los/as alumnos/as seleccionados/as, aun a pesar de que sus padres y madres no asistieron a ningún nivel educativo, e incluso ellas mismas y sus parejas no pudieron culminar sus estudios en el nivel medio (su instrucción educativa queda incompleta en el nivel primario), quieren que sus hijos/as obtengan credenciales educativas en el nivel medio. Puede verse que estas familias realizan grandes esfuerzos para que sus hijos/as estén escolarizados/as, y que también poseen muy elevadas expectativas educativas con respecto a sus hijos/as.

Por su parte, Quispe (2019) en su investigación tuvo como objetivo general indagar en torno del fenómeno de cerramiento o aislamiento del colectivo boliviano en el Valle Inferior del Río Negro, a través de enfoques teóricos que abordan las relaciones interétnicas y los procesos de conformación de las identidades colectivas.

El enfoque general de su investigación fue cualitativo. Pretendió interpretar y comprender un fenómeno en el marco de un procedimiento de análisis de base inductiva en el que no se buscó confirmar ninguna idea, sino ofrecer una interpretación del fenómeno estudiado a partir de la observación empírica realizada. El trabajo tuvo, por tanto, una perspectiva hermenéutica que se incorporó en un proceso de investigación flexible, que atendió dinámicamente a los hechos y a su interpretación, e intentó reconstruir la realidad partiendo de la perspectiva de los/as actores/as. Buscó comprender el fenómeno en un proceso dialéctico con una lógica inductiva apoyado en materiales empíricos como la entrevista, la experiencia personal, etc., utilizando métodos de recolección de datos no estandarizados, como la observación no estructurada, directa y participante, entre otros (Hernández Sampieri, 2018). El carácter flexible del diseño propuesto permitió reformular estrategias de acuerdo con los imponderables de la investigación, al mismo tiempo que revisar y ajustar los objetivos y las técnicas.

De esta manera, el trabajo produjo un acercamiento directo al objeto de estudio, con miras a la reconstrucción de las posiciones relacionales del colectivo migrante, lo que permitió comprender mejor las dinámicas que surgen al momento de vincularse con la comunidad de destino.

Las entrevistas se desarrollaron sobre la base del enfoque cualitativo, para abordar a las personas y su cultura. Quispe tomó la importancia del lenguaje y la construcción colectiva de las interpretaciones. Para llegar a los entrevistados empleó la técnica cualitativa de "bola de nieve"; se apoyó en la guía de los/as 
referentes más longevos/as, que son quienes señalaron a los/as potenciales entrevistados/as, según su criterio, y estos después sugirieron a otros posibles entrevistados.

Las observaciones directas fueron tomadas de manera escrita en un cuaderno de notas que contiene una serie de datos puntales de gran utilidad para la investigación. La recolección de datos incluyó el relevamiento de testimonios, conversaciones, observaciones intensivas, en el terreno en un trabajo de campo, que se prolongó durante un año, entre febrero de 2017 y marzo de 2018 de forma constante.

En ese período de tiempo concretó 34 entrevistas, algunas individuales, otras a parejas, lo que sumó a casi medio centenar de personas entrevistadas de la colectividad boliviana. Las entrevistas fueron realizadas en el área urbana de Viedma-Patagones, y en el área rural de San Javier, en una parte geográfica del Valle Inferior del Río Negro.

Si bien el objetivo general de la investigación se refería al cerramiento o aislamiento social de la colectividad boliviana, en sus testimonios el autor dio cuenta de entrevistas en las que diferentes jóvenes, entre ellos cuatro mujeres y dos varones, contaron que se encontraban cursando estudios en la universidad.

Por su parte, Cardoso (2019) investigó la multiterritorialidad como la experiencia de vivir en varios territorios en simultáneo, lo que implica una construcción histórica y social de esos territorios, cuyo espacio resultante redunda en un híbrido entre sociedad y naturaleza, materialidad e idealidad. A través de una metodología de carácter mixto (cualitativa y cuantitativa), en su estudio dio cuenta de cómo los migrantes de origen boliviano asentados en el rururbano norte de la ciudad de Santa Fe, Argentina, construyen territorialidades múltiples.

Observó un proceso de movilidad vertical que se ve reflejada en el fenómeno denominado "escalera boliviana" (Benencia, Quaranta y Souza Casadinho, 2009, p. 7), proceso en la que el migrante ingresa en calidad de peón, luego pasa por la mediería y el arriendo, hasta llegar a ser propietario. Bajo la forma de mediería, quien generalmente sale beneficiado es el propietario; el patrón paga al boliviano un precio inferior al cotizado en el mercado, por lo que el ingreso es paupérrimo. Por otro lado, las condiciones de vida de las familias bolivianas distan mucho de ser las óptimas. Viven en galpones, en habitaciones viejas de antiguos cascos rurales derruidos o en viviendas precarias con pisos de tierra y techos de zinc, baños exteriores $\sin$ saneamiento ni drenaje y carente de espacio para el aseo. La provisión de agua se realiza por bombas y no reúne los requisitos de potabilidad, el tratamiento de las aguas servidas no es el apropiado, por lo que conviven con serios problemas de parasitosis, sumados a una dieta alimentaria inadecuada, que genera desnutrición y predisposición a las enfermedades.

Concluye que, a partir del año 2000, se ha transformado y complejizado esa escalera con la aparición de nuevas posibilidades de inserción en la cadena hortícola y fuera de ella. Nuevas categorías, como arrendatario o propietario puestero, o comerciante desligado de la producción primaria, cobran relevancia. Con el transcurso del tiempo se han dado transformaciones sociales y demográficas: los hijos y nietos de los de bolivianos que arribaron en la década de 1960 a Santa Fe, Recreo y Monte Vera ahora son productores. Ellos lograron el incremento de las ganancias y unas mejoras progresivas en su calidad de vida. Algunos han podido construir viviendas de buena calidad, con materiales resistentes y servicios básicos (gas, agua corriente, luz eléctrica). En la unidad productiva se encuentran dotaciones propias como el tinglado de depósito de herramientas, algunas maquinarias y rodados (tractor, acoplados, fumigadoras, camioneta), lo que muestra que, de a poco, el trabajador ha podido capitalizarse. La jornada laboral es todavía "de sol a sol”, porque así lo exige ese tipo de cultivo, y en las labores participa la familia entera. Sin embargo, los jóvenes toman la actividad como complemento de sus estudios o de un empleo urbano. En su estudio señala que se han identificado horticultores que están cursando sus estudios universitarios.

Lemmi, Morzilli y Moretto (2018) indagaron acerca de los sentidos que construyen respecto de la educación las familias productoras de hortalizas del Gran La Plata. Abordaron la significación que le otorgan a la escolaridad, tanto en casos de adultos que deciden retomar sus estudios primarios y secundarios, como 
de jóvenes que se encuentran atravesando los estudios secundarios. Asimismo, analizaron las estrategias que ponen en juego para cumplimentar la escolarización en función de dichos sentidos.

En cuanto al marco teórico que orienta el presente trabajo, a partir del estudio de los sentidos, intentaron dar cuenta de las representaciones sociales, la perspectiva de los actores acerca del lugar que le atribuyen a la educación en sus estrategias familiares de vida. Buscaron rescatar la dimensión discursiva, simbólica, de aquellas representaciones sociales que son manifestadas en los relatos de los/las jóvenes y adultos/as investigados/as (Jodelet, 1989). Estas representaciones distan de ser individuales, pero son, en definitiva, a las que recurren los sujetos en cuestión para tomar sus decisiones. El anclaje de estas en la propia posición estructural que ellos/as ocupan no descarta la dimensión cultural que subyace en toda decisión individual (Giménez Montiel, 2005). Asimismo, retomaron la propuesta teórica de Pierre Bourdieu, quien, al hablar de estrategias, las conceptualiza como las prácticas (productivas, culturales, políticas, etc.) por medio de las cuales los agentes individuales o colectivos tienden, consciente o inconscientemente, a conservar o aumentar su patrimonio, para así conservar o mejorar su posición en la estructura de relaciones de clase (Bourdieu, 1988,2000).

La información la recabaron privilegiando la perspectiva cualitativa en el análisis de la documentación empírica. Por tanto, optaron por una investigación histórico-etnográfica, por ser la más adecuada dado el proceso de participación y el tipo de acercamiento a los actores sociales. Con ella se pretende reconstruir la perspectiva de los sujetos sociales acerca de las acciones que protagonizan, en su papel de intérpretes polémicos del mundo social (Batallán y García, 1992; Guber, 2001; Rockwell, 2009). Desde el abordaje metodológico etnográfico, llevaron adelante observaciones participantes y entrevistas en profundidad (semiestructuradas) a interlocutores seleccionados, a partir de una muestra teórica intencionada conformada por bola de nieve. Esta metodología les permitió reconstruir la perspectiva del actor social rescatando el sentido otorgado a las prácticas, y, de modo particular, aquellas referidas a las metas educativas de jóvenes y adultos/as integrantes de familias bolivianas del cinturón hortícola platense.

Concluyeron que, en los casos estudiados, el hecho de que sus hijos e hijas pudieran acceder a la educación pública con perspectiva de continuar los estudios hacia niveles superiores es un anhelo sentido que los/as reivindica en su posición de padres y madres, y que da sentido a su realidades de migrantes horticultores/as. Esto es especialmente fuerte en el relato de las madres. El futuro es visto como la posibilidad de tener "un título universitario", un "trabajo mejor", y, en ese sentido, la educación se transforma en una de las estrategias familiares de vida más sentidas, y, por ende, sostenida con más fuerza.

Luego, Diez, Novaro y Martínez (2017), en su investigación analizaron los modelos de identificación y expectativas educativas que se proyectan para las jóvenes generaciones de la población migrante boliviana en Argentina, y de los llamados bolivianos de segunda generación. El análisis se centró en la escuela secundaria, marco en el que reconstruyeron procesos de desigualdad, selectividad y distinción jerárquica. Abordaron el modo en que los mismos coexisten en tensión con los discursos igualitarios del sistema educativo y con las aspiraciones de continuidad identitaria de las organizaciones y familias migrantes residentes en la localidad donde desarrollaron su investigación, en el norte de la provincia de Buenos Aires.

Partieron de los paradigmas de asimilación, integración/exclusión e inclusión con investigaciones etnográficas en curso y problemáticas desde la antropología.

Concluyeron que parte del éxito, traducido en ascenso social o en la posibilidad de distanciarse de las situaciones más subalternas, se juega en las posiciones ocupadas y consolidadas en las organizaciones, el acceso a cargos directivos, la visibilidad en las fiestas comunitarias, la consolidación de microemprendimientos productivos y comerciales, y, particularmente, la escolarización y profesionalización de los hijos/as. Sobre esto último se detuvieron en distintas partes del texto.

En el 2016 realizaron en la misma localidad un trabajo etnográfico en la escuela media. En él advirtieron cómo a la tensión entre igualación y distinción como colectivo se agrega otra, más pensada en la línea de lo que Bourdieu describe como distinción, como búsqueda del éxito social, el estatus y el prestigio cultural 
(Bourdieu 1988), y que provisoriamente nominamos distinción jerárquica. Asociaron esta expectativa al deseo de prestigio, ascenso y reconocimiento de sus hijos, algo que les permita distinguirse de sus connacionales y distanciarse de los prejuicios dominantes en Argentina hacia esta población. Las expectativas de reconocimiento y éxito de las jóvenes generaciones trasladan demandas explícitas a la escuela y la proyección de una escolaridad prolongada; esto es, el "seguir siendo" y "ser alguien" que los adultos suelen expresar (Novaro en prensa). Subrayaron que debe considerarse también cómo opera esto en las distintas generaciones. Según las autoras, "ser alguien” es una categoría social que puede encontrarse en estudios sobre los sentidos de la escuela para distintas poblaciones "subalternas" de la región latinoamericana (Salazar, 2007). En particular remite a la función promocional de la escuela, un discurso histórico vinculado al mandato ilustrado y positivista que instituye a la escolarización como vehículo para la inserción ocupacional asalariada (Figari y Dellatorre 2004).

A partir de esto, Diez, Martínez y Novaro observaron que tal mandato promocional resulta particularmente relevante para preguntarse por formas de identificación colectiva e individual en relación a la escolaridad, ya que en general implica modos de desmarcación de posiciones e identidades sociales de origen (Martinic, 1995). En su investigación señalaron que este imaginario ya había sido abordado en el propio contexto boliviano por Salazar (2007), quien analizó esto en relación a la búsqueda de profesionalización asociada a estrategias de desmarcación de las actividades manuales, junto a las pertenencias étnicas y de clase asociadas a ellas. En lo que respecta al trabajo etnográfico de las autoras, las mismas dieron cuenta de situaciones donde los jóvenes suelen integrarse más o menos tempranamente al mercado de trabajo, y muchos de sus padres expresaron la intención de que sus hijos realizaran trayectorias educativas largas, no abandonaran los estudios, lograran posiciones socialmente valoradas a través de la titulación en carreras técnicas y universitarias. Pudieron ver que la apuesta por la escolarización de los hijos es vivida también como legado de un recurso al que las generaciones anteriores no tuvieron acceso. En este sentido, relataron cómo una dirigente sostenía que la mejor herencia que puede dejarse a los hijos es asegurar la continuidad de los estudios: "yo no les dejo casas de herencia, les doy el estudio". Por otro lado, les decía otro joven padre boliviano, integrante de las organizaciones de migrantes, que cursa sus primeros años en la universidad: "la educación viene a cumplir una función reparadora".

Sumado a esto, la directora les expresó en más de una ocasión durante el trabajo de campo a Diez, Martínez y Novaro interés en que los estudiantes tuvieran información de la universidad (incluso en el 2016 nos convocó para ello), y, a su vez, expresó también su preocupación por la pérdida de matrícula en los grados superiores. En tensión con lo señalado, según las autoras, la directora comentó en una de sus charlas: "En general son pocos los chicos que continúan estudiando, y los que sí, hacen profesorados. Los pocos que deciden hacer una carrera universitaria, suelen cursar un par de años de CBC y discontinuar" (Entrevista Diez-Novaro con la directora, registro 2016).

$\mathrm{Al}$ seguir indagando en las historias de vida, entre las apuestas familiares asegurar la continuidad de estudios superiores de Bety, una de las entrevistadas, aparece como prioridad, como una expectativa que se articula con el logro de posiciones económicas y mejora en el acceso al trabajo.

Concluyeron entonces que la continuidad de la escolarización se presenta para los migrantes bolivianos en Buenos Aires como una condición de integración a la sociedad nacional y también de superación de la imagen de pobreza y sumisión. Esto también parece funcionar como un mecanismo de diferenciación al interior del colectivo. En este contexto, la escuela (más allá de las tensiones con el nacionalismo excluyente que caracteriza las escuelas argentinas) parece ser un espacio legítimo para garantizar las apuestas por igualdad y distinción de los migrantes.

Desde una metodología cuantitativa, Bologna y Falcon (2012) buscaron describir los cambios en el volumen y la composición sociodemográfica de peruanos y bolivianos residentes en la ciudad de Córdoba, entre los años 2001 y 2008. Observaron la alteración sufrida por el patrón de asentamiento residencial de ambos colectivos, a través de la comparación de la distribución, a nivel barrio, en las dos fechas. 
Plantearon de manera hipotética que los cambios observados van más allá de las condiciones económicas de las áreas de origen y destino, para ligarse al desarrollo de redes migratorias en Córdoba, tanto las de ayuda mutua como las de contratación laboral.

Los primeros resultados mostraron que los nacidos en Bolivia constituyen una corriente antigua y con un ritmo de crecimiento estable a lo largo del periodo censal. No obstante, aparecieron ciertos resultados llamativos, como los cambios en términos de composición demográfica, educativos, e inserción laboral.

Según el censo 2001, el nivel educativo alcanzado por población boliviana de 20 años con estudios secundarios o más en la capital de Córdoba era, en el caso de los hombres, del 39,3\%, y en el de las mujeres, del $33 \%$; en total, el 36,3\%. Según el censo 2008, en cambio, el nivel educativo alcanzado por población boliviana con estudios secundarios o más era del 35,8 \% para los hombres y de 35,2\% para las mujeres; en total, $35,5 \%$.

Finalmente, Pizarro (2008) en su trabajo tuvo por objetivo poner en evidencia la vulnerabilidad de los bolivianos que residen en la región metropolitana de la ciudad de Córdoba y sus experiencias de exclusión y discriminación, aun cuando la actual normativa en Argentina reconoce los derechos civiles y sociales de los inmigrantes internacionales. A pesar de los recientes adelantos en la letra de la Ley $\mathrm{N}^{\circ} 25.871$, promulgada en diciembre de 2003 y sancionada en enero de 2004, con respecto al reconocimiento de los derechos humanos de los inmigrantes, los inmigrantes limítrofes son vulnerables, tanto estructural como culturalmente, y la vida cotidiana de un importante sector de esta minoría sigue estando atravesada por diversas jerarquías de etnicidad, ciudadanía, trabajo y sufrimiento.

El trabajo de campo que realizó entre junio de 2008 y agosto de 2009 consistió en la observación participante de diversas situaciones que configuraron las experiencias de vida de los inmigrantes bolivianos en la región metropolitana de la ciudad de Córdoba, junto con entrevistas etnográficas e historias de vida de algunos agentes sociales: los propios inmigrantes, sus patrones, sus vecinos, sus maestros, entre otros. Además, se realizaron entrevistas a funcionarios de diversos niveles estatales argentinos y bolivianos, y a integrantes de distintas asociaciones de inmigrantes bolivianos de Córdoba. Se realizó un análisis documental de la normativa pertinente y de diversos periódicos locales. Se analizaron datos estadísticos provenientes del Censo Nacional de Población 2001 y del Observatorio Ciudadano de la Ciudad de Córdoba. Además, en 2009 se participó en talleres y cine-debates vinculados con la problemática de las relaciones socioculturales entre inmigrantes regionales y argentinos que fueron organizados por la Secretaría de Derechos Humanos de la provincia de Córdoba y la Subsecretaría de Cultura de la Secretaría de Extensión Universitaria de la Universidad Nacional de Córdoba.

A pesar de que en dicho período la migración de origen boliviano a la Argentina se caracterizó por ser ruralrural, hubo un pequeño número de bolivianos que se dirigieron a las grandes metrópolis argentinas, tales como Buenos Aires, Córdoba y La Plata, y que provenían de clases medias y altas residentes en áreas urbanas bolivianas. Algunos eran exiliados políticos y otros migraban con el objeto de realizar estudios universitarios. La mayoría de los que se establecieron definitivamente en Argentina lograron alcanzar, con el paso del tiempo, una posición socioeconómica relativamente acomodada, ya sea como profesionales o como comerciantes.

Tal como lo señalaba Jenny, una de sus interlocutoras -que es hija de inmigrantes bolivianos y que se considera "culturalmente boliviana" - en una conversación que mantuvo en septiembre de 2008, hubo distintos momentos en la migración boliviana a Córdoba. El primero de ellos se remonta a la primera mitad del siglo XX: "Quienes vinieron en esa época eran universitarios, venían a estudiar, con las necesidades básicas satisfechas con dinero para pagar los estudios. Eran de clase social muy distinta, con recursos económicos y culturales muy distintos [de los inmigrantes bolivianos que vinieron después]" (Fragmento del diario de campo de septiembre de 2008).

Antes bien, se marcó cierto interés por la integración o, en términos de uno de sus interlocutores, por el “entremezclamiento" entre bolivianos y cordobeses en las entrevistas mantenidas con algunos bolivianos/ 
as -y sus hijos/as- que residen en Córdoba desde hace más de quince años y que lograron posicionarse de manera relativamente exitosa en la sociedad local.

Esta ubicación ventajosa con respecto a otros conacionales que residen en Córdoba puede apreciarse en diversos ámbitos. A nivel socioeconómico son profesionales, empleados públicos o del sector servicios, o bien son "patrones" por cuenta propia (en la construcción y la horticultura). En relación a su residencia, viven en áreas no segregadas de la ciudad. Con respecto a la trayectoria educativa, sus hijos asisten o han asistido a escuelas privadas y/o a la universidad. De hecho, entre este sector de la diáspora boliviana en Córdoba, la discriminación que sufren los bolivianos fue atribuida no tanto a cuestiones estructurales, sino más bien a la actitud de autodiscriminación que tendrían los inmigrantes, a su poca voluntad para integrarse y a características de su personalidad que se deberían a cuestiones étnico-raciales.

Cecilia, una joven que actualmente asiste a la universidad y que fue abanderada de una institución escolar de gestión privada en Córdoba, relataba algunas dificultades que tuvo en la infancia con sus pares debido a que usaba palabras distintas a las de sus amigos.

\section{CONCLUSIONES}

Luego de exponer todas las investigaciones que se han encontrado sobre la presencia de migrantes bolivianos/as en el sistema educativo superior en Argentina pudieron ver que cuatro de ellas fueron investigaciones cuantitativas (Sosa, 2016; Bologna y Falcon, 2012; Sala, 2008; Sangiácomo, 2002), ocho fueron investigaciones cualitativas (Morzilli, 2020; 2019; Quispe, 2019; Lemmi, Morzilli y Moretto, 2018; Diez, Novaro y Martínez, 2017; Rosas, 2014; Magliano, 2013; Martínez Espíndola, 2010), y dos fueron mixtas (Cardoso, 2019; Pizarro, 2008).

En sus análisis, en general, la mayoría dio cuenta, tanto mediante datos estadísticos como de testimonios, que migrantes bolivianos/as se encuentran asistiendo al nivel educativo superior. Esto se observó en diferentes territorios: Córdoba, Mendoza, Río Negro, Santa Fe, Capital Federal y provincia de Buenos Aires.

Sin embargo, observamos que una investigación (Rosas, 2014) en sus resultados mostró que los/as jóvenes migrantes de países vecinos no lograban incorporarse a la educación superior. Empero, al contrario que esta investigación, varias (Quispe, 2019; Cardoso, 2019; Sosa, 2016; Magliano, 2013; Bologna y Falcón, 2012; Martínez Espíndola, 2010; Sala, 2008; Pizarro, 2008; Sangiácomo, 2002) dieron cuenta de casos de jóvenes migrantes bolivianos/as en la educación de nivel superior. Mientras tanto otras (Morzilli, 2020; 2019; Lemmi, Morzilli y Moretto, 2018; Diez, Novaro y Martínez, 2017; Martínez Espíndola, 2010) hicieron énfasis sobre las expectativas de los/as jóvenes, como de sus madres y familias migrantes bolivianas, con respecto a que los/as mismos/as ingresaran en los estudios superiores.

Con respecto al capital cultural institucionalizado de los/as migrantes bolivianos/as en los diferentes momentos históricos y territorios, Sosa (2016) -desde la estadística y a nivel nacional-, Magliano (2013) y Pizarro (2008) - para el territorio de Córdoba- sostuvieron que las migraciones más antiguas tenían un capital cultural institucionalizado mayor que las migraciones bolivianas más recientes. Esto se diferencia de lo que observaron Bologna y Falcon (2012) para Córdoba, Martínez Espíndola (2010) para Mendoza; Sala (2008) a nivel estadístico y nacional, y de lo que señalaron Morzilli, (2020; 2019), Lemmi, Morzilli y Moretto (2018) para el periurbano platense.

En cuanto a las relaciones que pudieron observarse en los diferentes estudios, se advierte que solo dos investigaciones analizaron específicamente la inclusión de migrantes en Universidades Nacionales (Sosa, 2016; Sangiácomo, 2002).

Por último, luego del análisis de todas las investigaciones se ha reparado que todavía algunas dimensiones no han sido estudiadas. En este sentido, como ya han señalado algunas investigaciones sobre las expectativas e intenciones de jóvenes migrantes bolivianos/as provenientes de familias que se dedican a la horticultura y que aspiran a ingresar a los estudios en el nivel superior (Morzilli, 2020; 2019; Lemmi, Morzilli y Moretto, 2018), 
aún no existen investigaciones que den cuenta de estas experiencias en el ciclo superior desde un enfoque sociohistórico combinado con método etnográfico, que recupere a su vez la perspectiva interseccional.

\section{ReFERENCIAS}

Batallán, G., y García, J. F. (1992). Antropología y Participación, contribución al debate metodológico. PUBLICARen Antropología y Ciencias Sociales, (1).79-93

Benencia, R. (1999). El concepto de movilidad social en los estudios rurales. En: Estudios Rurales. Teorias, problemas y estrategias metodológicas. Norma Giarraca coordinadora. Argentina: La Colmena, pp. 77-95.

Benencia, R., Quaranta, G., y Souza Casadinho, J. (2009). Cinturón Verde de Buenos Aires. Cambios sociales y productivos. Buenos Aires: CICCUS.

Bertranou, E. (2002). Determinantes del avance en los niveles de educación en Argentina. Análisis empírico basado en un modelo probabilístico secuencial. Tesis de la Maestría en Economía. Universidad de la Plata.

Binstock, G. P., y Cerrutti, M. (2005). Carreras truncadas: el abandono escolar en el nivel medio en la Argentina. Argentina: Unicef.

Bologna, E., y Falcón, M. D. C. (2012). Tendencias de la migración peruana y boliviana en Córdoba. Un análisis a partir de datos censales. Trabajo presentado en el V Congreso de la Asociación Latinoamericana de Población. Montevideo.

Bourdieu, P. (1988). La distinción. Buenos Aires: Taurus.

Bourdieu, P. (2000). Los tres estados del capital cultural. Sociológica 5, 1-5. Recuperado de: http://sociologiac.net/bi blio/Bourdieu-LosTresEstadosdelCapitalCultural.pdf

Bracchi, C., Gabbai, M. I., y Causa, M. (2010). Estudiantes secundarios: Un análisis de las trayectorias sociales y escolares en relación con 269 dimensiones de la violencia. Trabajo presentado en VI Jornadas de Sociología de la UNLP 9 y 10 de diciembre de 2010 La Plata, Argentina. Universidad Nacional de La Plata. Facultad de Humanidades y Ciencias de la Educación. Departamento de Sociología.

Cardoso, M. M. (2019). Aproximación a las territorialidades múltiples en espacios rururbanos. Indagaciones sobre horticultores en Santa Fe, Argentina. Bitácora Urbano-Territorial, 29(2),81-88.

Diez, M., Novaro, G., y Martínez, L. (2017). Distinción, jerarquía e igualdad. Algunas claves para pensar la educación en contextos de migración y pobreza. Cuadernos del Instituto Nacional de Antropología y Pensamiento Latinoamericano, 26(2), 23-40. Recuperado de: http://revistas.inapl.gob.ar/index.php/cuadernos/article/view $/ 1017$

Domenach, H., Celton, D. Y Alvarez, M., Bologna (1998). La comunidad boliviana de Cordoba: caracterization (1996) yproceso migratorio.

Filmus, D. (2010). La educación y el trabajo para la inclusión social de los jóvenes. Revista de Trabajo, 6(8), 177-198.

Guber, R. (2001). La etnografia: método, campo y reflexividad. Buenos Aires: Norma.

Hernandez Sampieri, R. (2018). Metodología de la investigación: las rutas cuantitativa, cualitativa y mixta. México: McGraw Hill.

Lemmi, S. (2015). Conflicto y organización en la horticultura del Gran La Plata (Buenos Aires, Argentina), 1994-2002. Revista Interdisciplinaria de Estudios Agrarios (43), 27 - 54

Lemmi, S., Morzilli, M., y Moretto, O. (2018). Para no trabajar de sol a sol. Los sentidos de la educación en jóvenes y adultos/as integrantes de familias migrantes bolivianas hortícolas del Gran La Plata - Buenos Aires, Argentina. RUNA, archivo para las ciencias del hombre, 39(2), 117-136.

López, N. (2002). Estrategias sistémicas de atención a la deserción, la repitencia y la sobreedad en escuelas de contextos desfavorecidos. Un balance de los años 90 s en la Argentina. Buenos Aires: IIPE/UNESCO.

Macri, M. (2005) El Trabajo Infantil No Es Juego: Investigaciones Sobre Trabajo InfantoAdolescente en Argentina (1900-2003). Buenos Aires: La Crujía. 
Martínez Espínola, M.V.(2010). Experiencias migratorias de mujeres bolivianas residentes en Mendoza (Tesis de grado). Universidad Nacional de Cuyo, Facultad de Ciencias Políticas y Sociales, Mendoza.

Martinic, S. (1995). Principios culturales de la demanda social por educación. Un análisis estructural. Pensamiento educativo, 16(1), 313-39.

Magliano, M. (2013). Los significados de vivir "múltiples presencias": Mujeres bolivianas en Argentina; El Colegio de la Frontera Norte. Migraciones internacionales, 7(1),165-195. Recuperado de: http://hdl.handle.net/11336/8197

Morzilli, M. (2019). Entre la quinta y la escuela, una bifurcación en la "escalera boliviana". Trayectorias escolares y socioproductivas de jóvenes de familias horticultoras bolivianas en el periurbano platense (2011-2017) (Tesis doctoral). Universidad Nacional de La Plata, Ensenada.

Morzilli, M. (2020). Trabajo juvenil y trayectorias escolares de jóvenes migrantes bolivianos: Estudio de casos en el periurbano hortícola platense. Trabajo y sociedad, (34), 309-329.

Padawer, A. (2008). Cuando los grados hablan de Desigualdad: Una etnografía sobre iniciativas docentes contemporáneas y sus antecedentes históricos. Teseo

Pizarro, C. (2008). La vulnerabilidad de los inmigrantes bolivianos como sujetos de derechos humanos: experimentando la exclusión y la discriminación en la región metropolitana de la ciudad de Córdoba. Argentina: Ministerio de Justicia, Seguridad y Derechos Humanos.

Quispe, F. E. (2019). Aislamiento social del colectivo migrante boliviano en el Valle Inferior del Río Negro. (Tesis de grado). Universidad Nacional de Río Negro, Río Negro. Recuperado de: https://rid.unrn.edu.ar/jspui/handle $/ 20.500 .12049 / 3529$

Ringuelet, R., Attademo, S., Archenti, A.. y Salva, M. C. (1991). La producción hortícola en el Partido de La Plata: cuestión productiva, cuestión social, cuestión ambiental. Revista Cuestiones Agrarias Regionales, (6).

Rockwell, E. (2009). La experiencia etnográfica. Historia y cultura en los procesos educativos. Buenos Aires: Paidós.

Rosas, C. A. (2014). Yo pensaba que era como en las películas... Reflexiones en torno a los jóvenes latinoamericanos y las migraciones internacionales. RedEtis Tendencias en foco, 27, 1-20. Recuperado de: http://hdl.handle.net/ $11336 / 35463$

Sala, G. (2008). Perfil educativo y laboral de los nuevos y viejos migrantes regionales censados en Argentina y Brasil. Migraciones internacionales, 4(4), 73-106. Recuperado de: http://www.scielo.org.mx/scielo.php?script=sci_art text\&pid $=$ S1665-89062008000200003\&lng=es\&tlng=es

Sangiácomo, M. (2002). Migrar para estudiar. Los estudiantes bolivianos en la Universidad Nacional de La Plata. Sociohistórica, 11-12, 1.17. Recuperado de: https://www.sociohistorica.fahce.unlp.edu.ar/article/view/SHn11$12 \mathrm{a} 10$

Sassone, S. M. (2009). Breve geografía histórica de la migración boliviana en la Argentina. En Ameztoy, M. V. (org.), Buenos Aires boliviana. Migración, construcciones identitarias y memoria. Temas de Patrimonio Cultural 24, Gobierno de la Ciudad de Buenos Aires, Ministerio de Cultura de Argentina, Buenos Aires.

Sosa, M. (2016). Migrantes en el sistema educativo argentino. Un estudio sobre la presencia de alumnos extranjeros en los estudios de nivel superior. Revista iberoamericana de educación superior, 7(19), 97-116. Recuperado de: h ttp://www.scielo.org.mx/scielo.php?script=sci_arttext\&pid=S2007-28722016000200097\&lng=es\&tlng=es

Terigi, F. (2009). Las trayectorias escolares. Del problema individual al desafío de la politica educativa. Buenos Aires: Ministerio de Educación de la Nación.

\section{Notas}

1 Según Sassone (2009), la migración desde 1991 creció principalmente en tres grupos: "los de Paraguay, Bolivia y de Perú... Bolivia, en 1980, reunió el 6 \% de extranjeros y ocupó el quinto lugar tanto en ese censo como en el siguiente (9 \%); mientras que en 2001 dio un salto cuantitativo: se ubicó en el segundo lugar con el $15 \%$ del total de residentes no nativos. La Argentina es el primer país de destino para la población boliviana... En los años setenta, esta migración alcanzo la mayor difusión espacial entre todas las corrientes migratorias limítrofes. Los bolivianos empleados por demandas del sector agrícola coordinaron (sistemática y organizadamente) tareas estacionales a lo largo del año agrícola incluso 
con empleos en las ciudades; la tendencia a la fijación residencial en áreas urbanas. Las economías regionales extrapampeanas demandaban trabajadores de temporada y se advirtió su activa presencia en la horticultura en cinturones verdes (Benencia y Karasik, 1994; Benencia, 2004 y 2006) y en valles de regadío, incluso en la región pampeana. Se activaron las redes migratorias entre familiares y paisanos. Las familias fueron protagonistas de la migración y residían en áreas urbanas, con frecuencia en villas miseria en áreas urbanas y rurales del país".

2 Jóvenes de familias migrantes bolivianas insertas en la producción de hortalizas del periurbano de la ciudad de La Plata (provincia de Buenos Aires, Argentina).

3 Benencia se refiere a la existencia de una escalera boliviana. Con la misma está haciendo alusión a una "escalera" de ascenso social que vislumbró en sus estudios sobre los horticultores migrantes de origen boliviano en la década del 80 . El autor constató para esos años la existencia de una "escalera boliviana" de ascenso social y económico experimentado por dichos migrantes, que comenzaron como peones y fueron consolidándose de a poco junto al trabajo de toda su familia como peones medieros hasta convertirse en arrendatarios (Benencia, 1999).

4 Según Bourdieu (2000), el capital cultural institucionalizado serían aquellos conocimientos y habilidades que se adquieren y que están certificados a través de los títulos, en tanto que son papeles que habilitan mediante un ente autorizado (con autoridad) a otorgar un certificado. 